\title{
A PESQUISA EM HISTÓRIA DA EDUCAÇÃO - TESTEMUNHO DE UM AUTOR: ENTREVISTA COM AGUSTIN ESCOLANO \\ DOI: http://dx.doi.org/10.1590/2236-3459/65230
}

\section{RESEARCH IN HISTORY OF EDUCATION - TESTIMONY AN AUTHOR: INTERVIEW WITH AGUSTIN ESCOLANO}

\author{
Maria Helena Camara Bastos \\ Pontifícia Universidade Católica do Rio Grande do Sul, Brasil.
}

$\cos 80$

Como aconteceu, na sua trajetória, seu encontro com a história da educação?

$\mathrm{M}$ is primeras reflexiones acerca del carácter histórico de la educación fueron muy tempranas. En los comienzos de mi vida universitaria, cuando mis intereses lectores giraban en torno a diversos campos disciplinarios Historia, Filosofía, Sociología y humanidades en general -, me llamaba la atención que las prácticas empíricas de enseñanza, desde las elementales a las superiores, fueran tan fieles a la tradición y a la costumbre. La sociedad cambiaba, como podía observar, a ritmo activo de formas, medios y lenguajes, pero la educación formal seguía obstinadamente refractaria a las innovaciones. Ello me llevaba a preguntarme por los motivos que pudieran explicar tan largo y asentado conservadurismo.

Esta era sin duda una inquietud que tenía que desembocar obligadamente en la historia de la escuela y de las instituciones de formación, una historia que podía tal vez ayudar a desvelar algunas de las claves de la cultura escolar vigente, hasta entonces solo abordada desde la historia de las ideas y desde la historia política de la educación. Una de estas formas de hacer historia, la orientada a las teorías, me parecía un túnel opaco que oscurecía u ocultaba la realidad; la otra - la historia de las políticas - era un puente que la sobrevolaba. La de las ideas se agotaba en el viejo idealismo; la de las políticas abocaba a explicaciones utopizantes y voluntaristas. Mejor era sin duda buscar en la fenomenología etnográfica, y en la hermenéutica de la acción, las claves de un empirismo de nuevo cuño que pudiera educar la mirada de los historiadores y de los enseñantes 
hacia una historia de las prácticas escolares discursivas, en las que se pudieran sustentar los relatos y las experiencias emancipadoras, así como las interpretaciones de la experiencia vivida.

Mediada ya mi carrera universitaria, tuve la fortuna de encontrarme con una competente profesora de historia de la educación, María Ángeles Galino, antes también tuve buenos profesores de historia de España y Universal y de humanidades en general. Mi maestra era a la vez una intelectual culta, exigente y rigurosa, que contextualizaba los análisis históricos de la educación en diversas perspectivas disciplinarias, y no solo en la pedagogía. Por su talante y su formación destacaba claramente en el cuadro académico de la época, más sujeto a la vieja escolástica o al nuevo positivismo funcionalista que estaba en curso. Ello me llevó a hacer buenas lecturas, tanto de autores clásicos como de los modernos, así como a descubrir líneas emergentes de pesquisa en diversas ciencias humanas, así como en otras disciplinas historiográficas que implicaban en la práctica investigativa a todas las ciencias del hombre, la sociedad y la cultura.

En mis primeras experiencias como docente, en varios niveles del sistema educativo, seguí con estas inquietudes. $\mathrm{Y}$ en mi ejercicio como inspector escolar, en las provincias de Santander y Barcelona, viví en directo el proceso de reforma de la educación en España entre finales de los años sesenta y los comienzos de los setenta observando varios hechos: las fuertes resistencias de los docentes al cambio; el voluntarismo tecnocrático de los reformadores externos, sobre todo de los agentes de la administración; la ruptura acrítica de la nueva realidad con las mejores tradiciones, las hoy llamadas buenas prácticas; la destrucción del patrimonio material de la escuela y su sustitución por medios modernos que no se insertaban bien en el cotidiano de las aulas ni se acomodaban al habitus de los enseñantes; la recepción de innovaciones exógenas que obedecían a la lógica de las modas y vanguardias y no a demandas internas del sistema... Ello me llevó a comprender, interpretar y valorar la complejidad de los procesos de modernización educativa y a intentar explicar el sentido histórico que habían de tener todas las mudanzas racionalmente orientadas.

Mi investigación doctoral, que llevé a cabo entre 1964 y 1970, ponía en relación la aparición de las nuevas formas de educación técnica que emergieron con los cambios económicos y sociales acaecidos durante la llustración y el despliegue de la revolución industrial en España, un proceso histórico sumamente complejo e interesante para entender la entrada de mi país en la Modernidad y en la revolución burguesa. Esta experiencia investigadora reforzó mis anteriores motivaciones e inquietudes y me abocó a centrar el interés intelectual en la historia de los hechos económicos y sociales, incluidas las prácticas culturales que los acompañaron, alejándome de los viejos idealismos y voluntarismos que habían modelado la historiografía tradicional. Una vez más, la praxis investigadora, que me acercó a la nueva historia económica y social, al tempo que inducía cambios en la misma episteme de la historia educativa. 
Figura 1 -

Imagen del profesor Agustín Escolano Benito tomada en la biblioteca del Ceince.

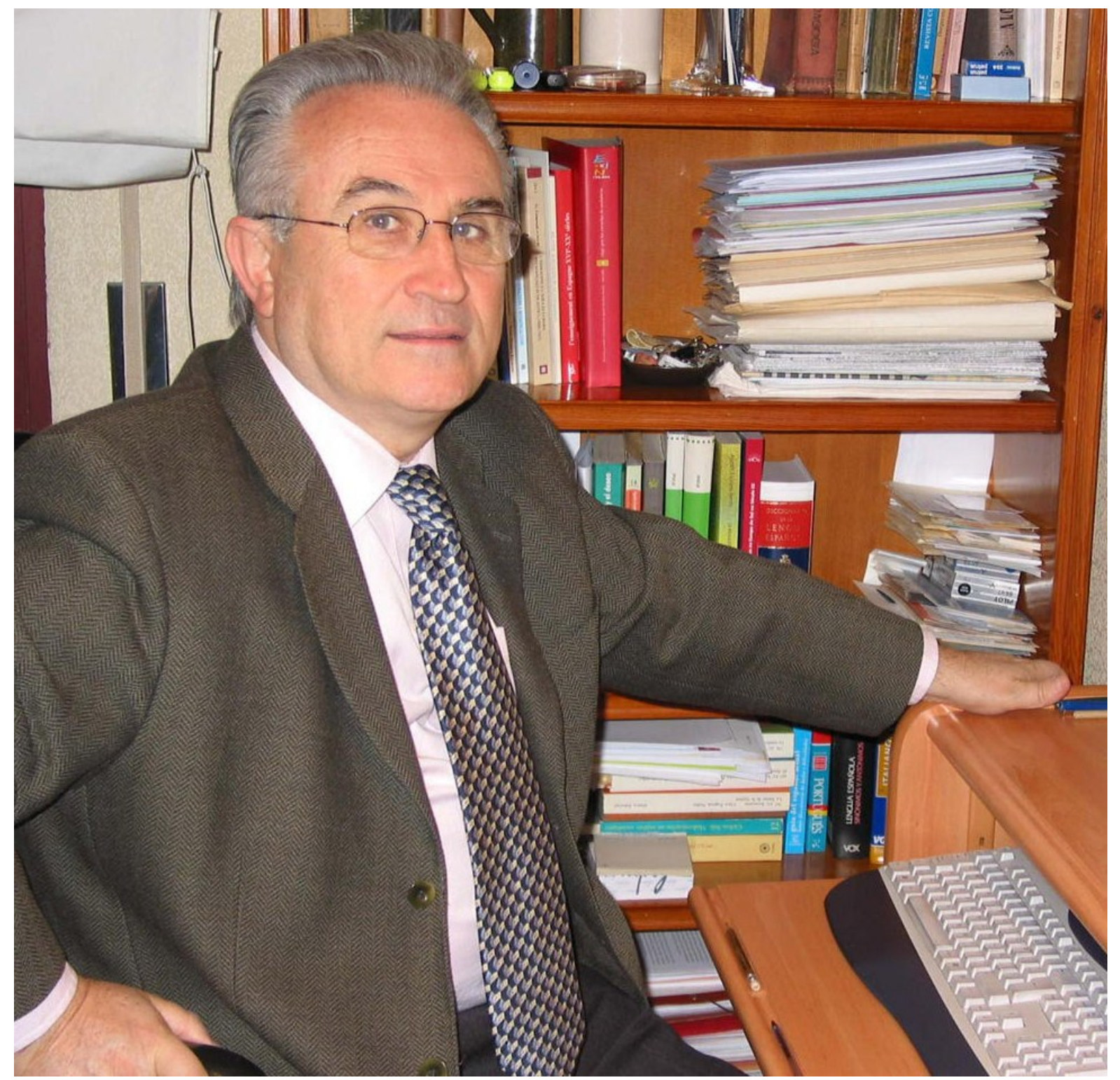

Ao longo da sua carreira, quais os temas de pesquisa que retiveram a sua atenção?

Han sido varios y diversos. El aglutinante de todos ellos, o al menos uno de los ejes nucleares más significativos, es la cultura, o las culturas, de la escuela. En este campo, mis trabajos han versado acerca de los siguientes temas específicos: los espacios o arquitecturas de la escuela; los tiempos y cronogramas institucionales de la educación formal; la génesis y configuración textual de la manualística; la ya citada cultura empírica de la educación institucionalizada; la memoria y el patrimonio educativo como base de la educación histórica de la ciudadanía; el cambio formativo asociado a la nueva cultura de la sostenibilidad; los procesos históricos de mudanza, innovación y modernidad; la cultura 
material, la etnohistoria y la arqueologia escolar; la historia comparada de la escuela en la Europa del Sur y en América Latina; la historia de la alfabetización en España; los viajes por las regiones de España y la construcción de la escuela como espacio público y como institución nacionalizadora. Temas, como se puede observar, plurales, aunque tejidos por un transversal que los cohesiona: la configuración sociohistórica de la escuela y de la cultura que se ha codificado en ella a través de las prácticas y discursos verificables.

Figura 2 y 3 -

Historia escuela y La España cubista.

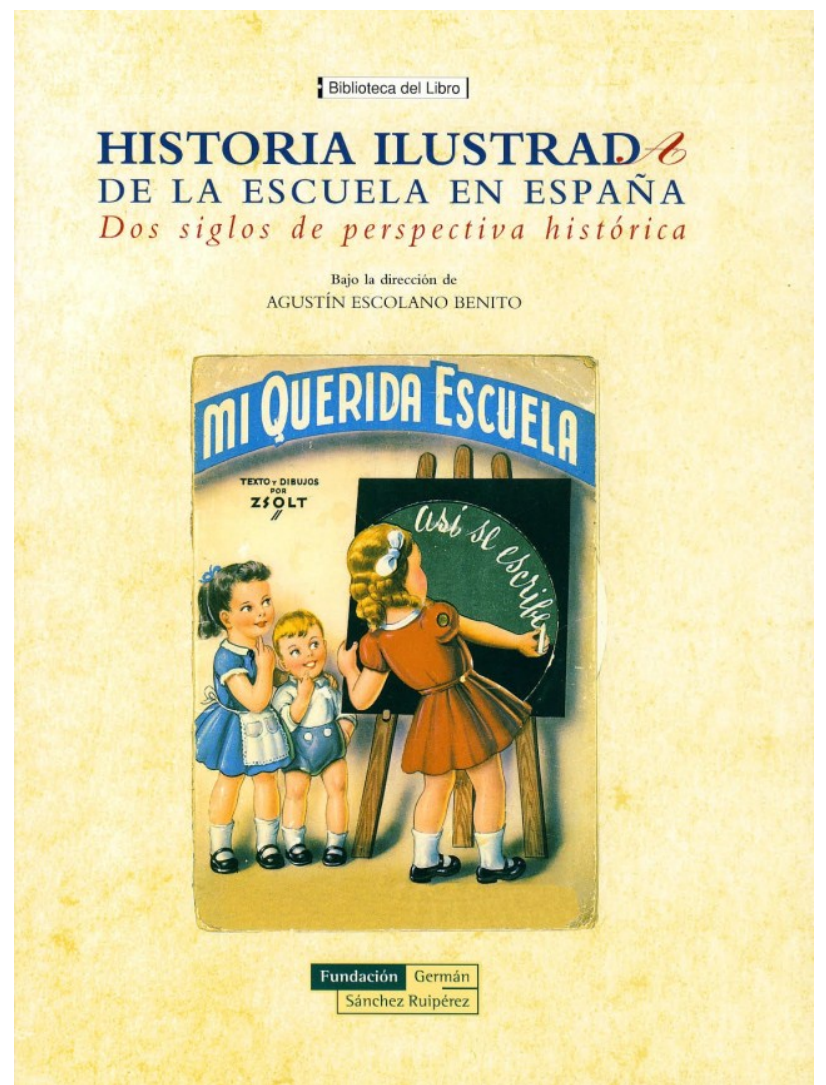

\section{La España cubista de Luis Bello}

Visiones desde la escuela

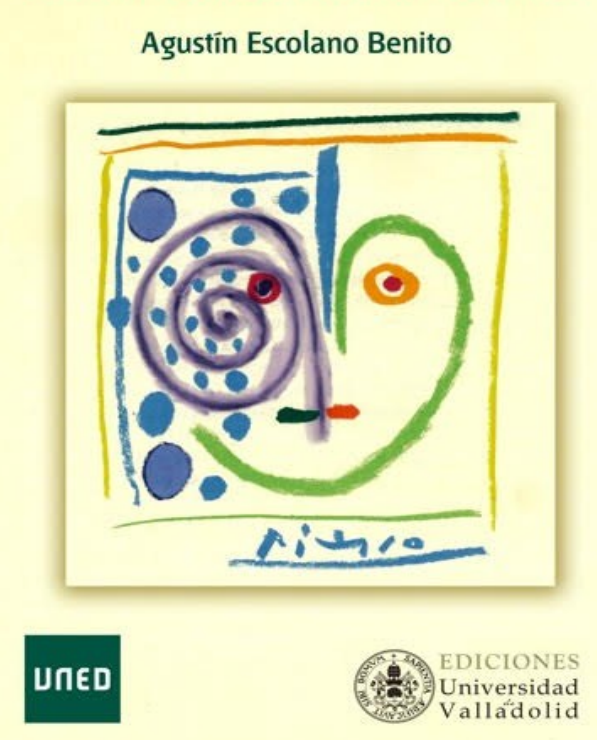

Cubiertas de dos obras representativas de mis investigaciones académicas: Una aparecida en el año 2006 versa sobre la construcción histórica de escuela en España, en muchos de los aspectos señalados anteriormente como líneas de investigación. La otra, de 2015, es un texto verbo-icónico, ilustrado con imágenes, que ofrece una representación visual y textual de la idea de España como construcción nacional y de sus regiones y nacionalidades desde la historia de la escuela, tal como esta se nos ofrece en los libros de viajes y en otras fuentes materiales, iconográficas y etnográficas.

En otro orden de cosas, también me ocupé en mis primeros estudios en investigaciones relativas a la construcción histórica del conocimiento pedagógico y a sus supuestos epistemológicos, así como en trabajos relacionados en torno a la planificación y gestión de la educación en los países mediterráneos. Estos últimos estudios se llevaron a cabo por encargo del Centro Europeo de Educación Superior de la Unesco, ubicado en Bucarest, en la época en la que fue consultor de esta organización internacional. En los años setenta/ochenta del siglo anterior, siendo catedrático y director del Instituto de Ciencias de la Educación de la Universidad de Salamanca, participé en diversas reuniones científicas que tuvieron lugar en varias sedes europeas, occidentales y del 
Este. En etapas precedentes ya había dedicado atención, en Santander y en Oviedo, a trabajos relacionados con la supervisión y la prospectiva de la educación. Todos estos programas tenían un destacado contenido historiográfico.

Figuras 4 y 5 -

Imagen de la cubierta de las dos obras Historia ilustrada del libro escolar en España.

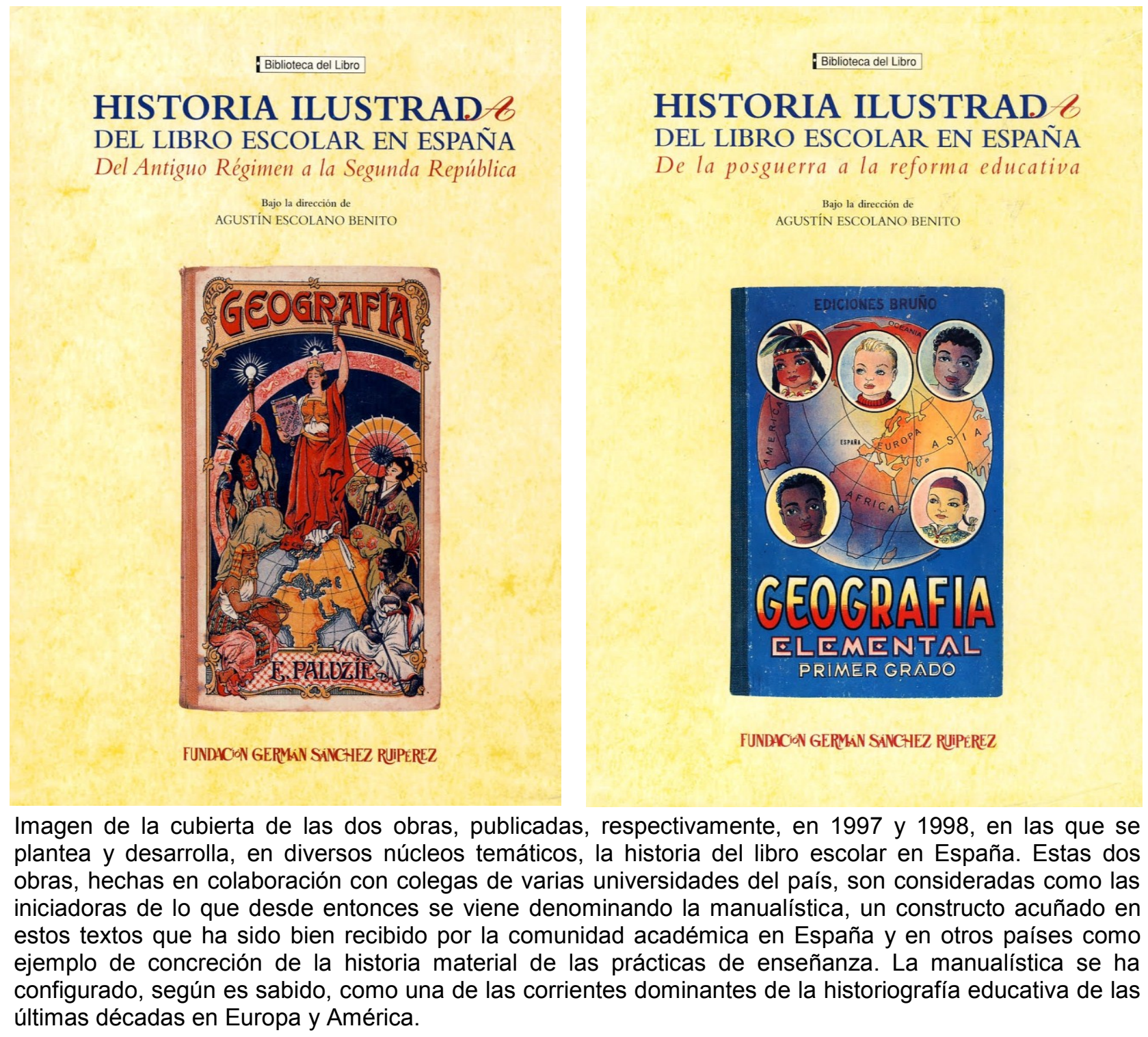

Nessas condições, como ocorreu a fundação do Centro Internacional de la Cultura Escolar?

El Ceince tiene uma larga protohistoria si se tiene en cuenta el proceso acumulativo de las fuentes bibliográficas y los materiales etnográficos que forman parte de su importante acervo documental. Hace unos cuarenta años decidí iniciar la tarea silenciosa de salvamento del patrimonio etnohistórico de la escuela. En aquella época, el signo modernizador de las administraciones de las primeras reformas tecnocráticas españolas del tardofranquismo amenazaba por destruir y borrar los objetos-huella en los que aún se podían leer la memoria de la educación y los códigos del oficio de enseñante. Mis 
contactos con la realidad, en mis visitas continuas a las escuelas como inspector de enseñanza en las circunscripciones de Cantabria y Barcelona, me mostraba a diario cómo el ajuar de las viejas instituciones de formación estaba a punto de desaparecer al ser sustituido por los nuevos artilugios del audiovisual y de otras tecnologías de la época.

Debió despertarse en mi entonces una especie de "instinto arqueológico a futuro" que me invitaba a ejercer resistencia frente a las amenazantes advertencias que abocaban a la desmemoria y al olvido de una cultura que estaba implícita en las materialidades escolares obsolescentes. Aquellos textos, iconos, objetos y relatos, a veces arcaizantes, habían de ser salvados en una especie de Arca de Noé que un día pudiera dar origen a un centro de memoria de la escuela, necesario no sólo para los profesionales de la enseñanza del porvenir sino para la formación histórica de toda la ciudadanía ilustrada.

Durante las pasadas décadas he ido ampliando y diversificando esta búsqueda de fuentes, al tiempo que madurando un proyecto concreto de puesta en valor del patrimonio histórico-educativo como bien de interés general y público. Al coincidir esta estrategia con la creciente revalorización que la sociedad de nuestro tiempo ha venido atribuyendo a la cultura material, mi vocación se vio sin duda reforzada, lo que cristalizó con el apoyo a la iniciativa de creación de un centro de memoria ad hoc por parte de la Unión Europea. De esta manera, la escuela se constituía en un valor que venía a ser eje estructurarte de la sociabilidad común de la ciudadanía y de las identidades narrativas personales. Desde que la escuela se hizo obligatoria y universal su cultura es compartida por todos, y su museización es una mediación para construir narrativas de encuentro entre personas, colectivos e incluso generaciones.

En una perspectiva de mayor proximidad, el Centro Internacional de la Cultura Escolar entró en una fase plenamente operativa a comienzos de la nueva centuria. Puede considerarse un hito inicial de despegue de la vida del centro la visita que hicieron las documentalistas responsables de la biblioteca del Instituto Georg Eckert, de Braunsweigh, Alemania. Gisela Teistler y Cristina Mainz exploraron, en el año 2002, los materiales de lectura utilizados en su estudio histórico-comparado publicado poco después sobre las lecturas escolares en las culturas autoritarias de la Europa occidental: la Alemania nacional-socialista, la Italia fascista y la España franquista.

En 2003 se constituyó la Asociación Schola Nostra, integrada por un grupo de profesores de las Universidades de Valladolid, Burgos y Salamanca, todas ellas de la Comunidad de Castilla y León, que fue la que impulsó la creación del Ceince como centro dedicado a la recuperación y estudio de la memoria y el patrimonio de la educación, con énfasis en la manualística, y al análisis crítico y debate del hecho escolar en la sociedad del conocimiento. La plena apertura al público del centro se produjo a comienzos del año 2006, es decir, hace ahora diez años. Los miembros del grupo fundador del Ceince eran, en su mayor parte, discípulos de mis entornos académicos de Salamanca, Burgos y Valladolid. Las universidades de Salamanca y Valladolid son las dos más antiguas del país. También se asociaron desde su origen al proyecto varios enseñantes de otros niveles educativos con antecedentes en el campo de la innovación pedagógica, e incluso agentes sociales del amplio campo de la educación no formal. Después, el Círculo de 
Amigos del Ceince se ha ampliado a varios centenares de colaboradores de casi todas las regiones de España y de un buen número de países de la Unión Europea y de América Latina, principalmente.

Figura 6 y 7 -

Edificio Ceince y biblioteca.
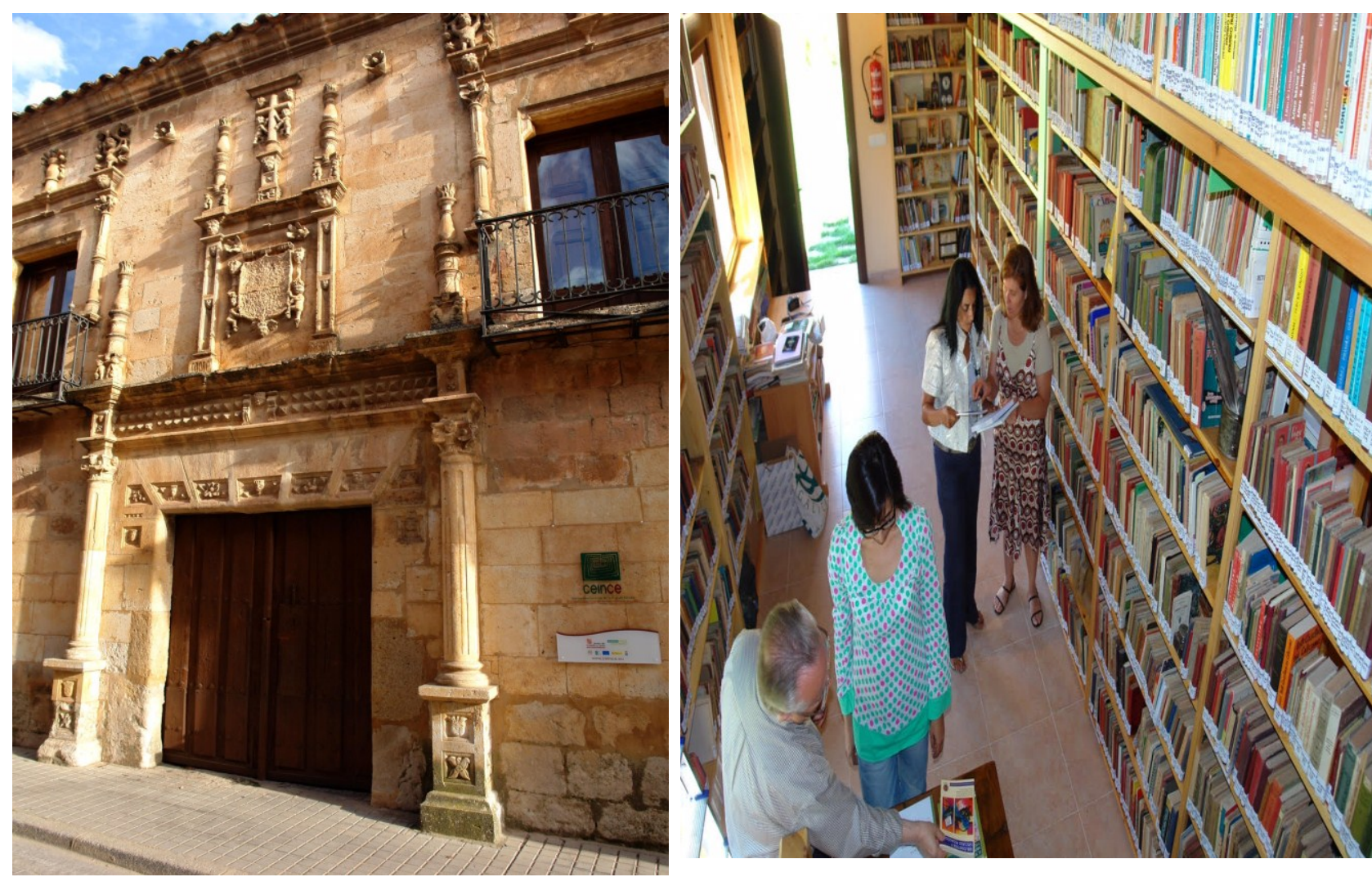

Imagen del edificio histórico del Ceince, un palacio renacentista del siglo 16 adscrito a nobleza castellana de la época, declarado monumento artístico nacional. En este contenedor, que se compone de cuatro salas, se encuentra el espacio museográfico denominado Mi querida escuela. Derecha: interior de uno de los cuatro contenedores de la biblioteca que alberga un conjunto de más de cincuenta mil volúmenes, con una parte destacada dedicada a los manuales escolares. En la imagen, del año 2008, aparecen varias doctorandas de las universidades portuguesas de Lisboa y Évora.

En su origen, el Ceince fue una iniciativa apoyada por la Unión Europea (Programa Leader), la Junta de Castilla y León y la Fundación Germán Sánchez Ruipérez, una entidad de larga tradición en la cultura del libro. A lo largo de todos estos años, nuestro centro se ha abierto a toda la comunidad nacional e internacional y ha firmado convenios de cooperación con 23 entidades, generalmente universitarias, de España, Francia, Italia, Portugal, Brasil, México, Chile, Argentina y otros países de Europa y América.

\section{Quais são as principais contribuições do Ceince no campo da história da educação?}

Sintetizando podríamos decir que el Ceince ha contribuido, entre otras cosas, a:

- Reunir, catalogar, custodiar y difundir un gran acervo de documentos de diverso tipo en los que se sustenta la memoria y el patrimonio de la cultura escolar. 
- Dentro de este acervo destaca la biblioteca del centro, constituida hoy por más de cincuenta y cinco mil volúmenes, de los que $3 / 4$ partes son manuales escolares. En esta colección ha comenzando a tener cada vez más presencia visible el subfondo de libros de unos treinta países.

- Abrir y mantener el debate público, en perspectiva comparada e internacional, acerca de cuestiones que vinculan la memoria con la actualidad: intercultura, cuestiones de género, giro digital, desarrollo sustentable, culturas y transiciones, sociedad del conocimiento, hermenéutica, profesión docente.

- Servir de foro al diálogo entre diversas culturas, con énfasis en las relaciones entre los países de Europa y América. Hay que señalar asimismo que por el Ceince han pasado profesores e investigadores de todos los continentes.

- Favorecer las estancias de investigación de profesores, pos-graduados y doctorandos de todo el mundo. En este momento se computan en cerca de 400 los investigadores que han estado trabajando en el centro en estancia de corta y media duración. Nuestra web ofrece en sus memorias y en los papeles del Ceince el historial detallado de estas acciones, con indicación de las temáticas y las instituciones de procedencia de los investigadores.

- Contribuir a la educación histórica de la ciudadanía. Son más de doce mil los visitantes, no sólo especialistas en educación sino de todos los sectores ciudadanos, que han pasado por el museo pedagógico "Mi Querida Escuela".

\section{Como analisa as relações que o Ceince teve e tem com os pesquisadores e a pesquisa brasileira?}

Excelentes. Brasil es sin duda una de las potencias mundiales en nuestra área. $Y$ desde luego es seguramente el país exterior del que procede un mayor número de pesquisadores visitantes del Ceince. En el contacto continuo con los investigadores e investigadoras de Brasil los españoles hemos aprendido muchas cosas.

Hoy mismo, cuando estoy cerrando las respuestas a este cuestionario se encuentran trabajando em el Ceince tres jóvenes posgraduadas de la Pontificia de Universidad de Sâo Paulo: Kelly Ludkiewicz, que analiza fuentes relativas a las campañas de alfabetización de sujetos adultos a mediados del siglo último; Joana Borges de Faria, que consulta las láminas didácticas y materiales murales; Tainá Pinheiro dos Santos, que trabaja en cuestiones de educación estética, cotejando los modelos artísticos del universo exterior a la escuela con los diseños que se gestan en las prácticas y materiales de enseñanza.

El Ceince se enriquece con la constante interacción con los miembros de las comunidades académicas cariocas que nos visitan y que trabajan en temas como la manualística, la cultura material, el mundo de la infancia y otros muchos centros de interés común. El próximo mes tendremos un encuentro con cualificados/as colegas de las universidades de Campinas y Santa Catarina que tratará cuestiones relacionadas con las materialidades de la cultura escolar. 
Figura 8 -

Copertina del libro La cultura empirica della scuola.

\title{
Augustin Escolano Benito
}

\section{La cultura empirica della scuola}

\author{
Esperienza, memoria, archeologia
}

con una postfazione di Umberto Margiotta
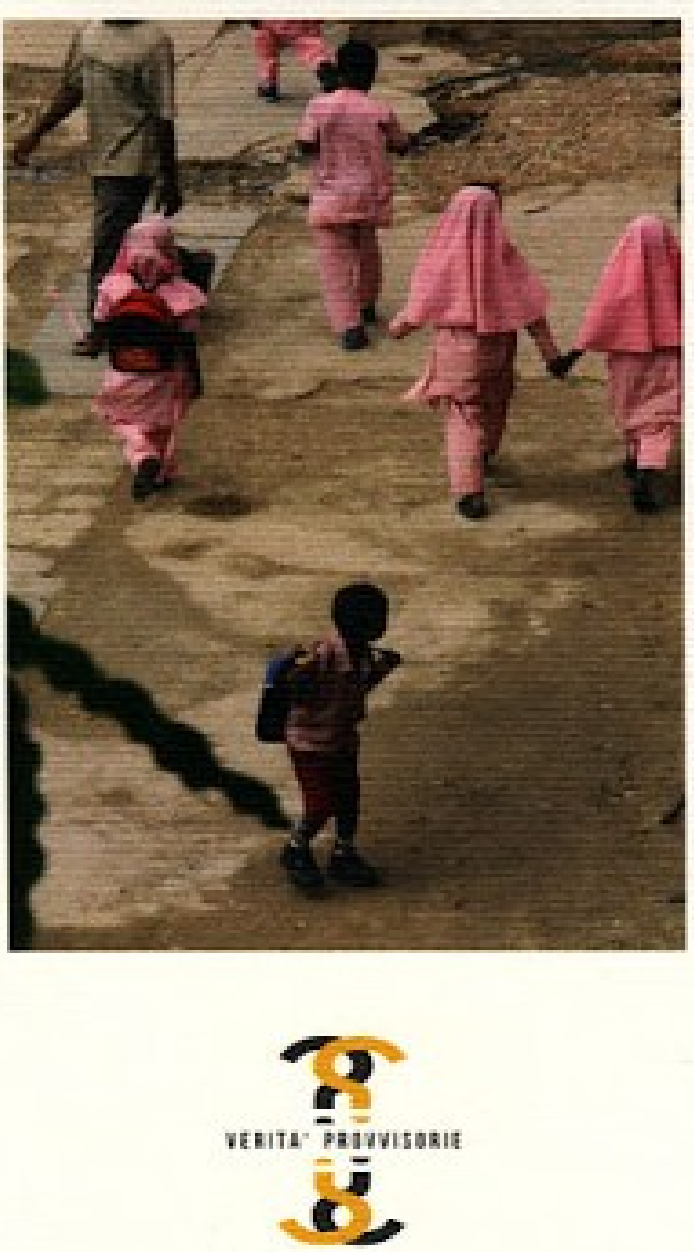

Me parece interesante destacar que mi último libro, publicado en Italia por la editora Volta la Carta de Ferrara, en 2016, venga a cerrar aquella pregunta pragmática y fenomenológica de mis motivaciones intelectuales iniciales en el campo de la historia de la educación. Su título - La cultura empirica della scuola: esperienza, memoria, archeologia - da cuenta de la coherencia que une mis orígenes académicos y mis últimas preocupaciones, en un arco temporal de más de medio siglo que se asemeja a un cierre hermenéutico. Esta obra aparecerá, traducida al portugués, en Brasil, en fecha próxima. 
Segundo a sua experiência, que reflexões faz sobre as perspectivas da história da educação na Espanha?

La historia de la educación en España goza de buena salud si la valoramos por sus producciones. A pesar de que las universidades, guiadas por el nuevo pragmatismo tecnicista, la reduzcan a mínimos en sus currículos de pedagogía, ciencias de la educación y formación de docentes, nuestra disciplina sobrevive y se afirma en el mundo académico y en la sociedad.

Como disciplina, tiene un mayor desarrollo en su proyección investigadora. En este sentido, la historia educativa no solo interesa a quienes trabajan en educación y formación de profesores. Atrae cada vez más la atención de los historiadores generales, que buscan en ella la explicación genética de los procesos de formación de los ciudadanos como hecho constitutivo de las personas y de las colectividades, y también de las élites.

Igualmente interesa desde hace años a los historiadores de la economía, como mediación que explica la formación de capital humano y que implementa en cada momento histórico la estructura del desarrollo de las fuerzas productivas y los comportamientos de consumo en la sociedad.

Es asimismo de interés para la historia de la política, toda vez que la educación formó a los ciudadanos, se instrumentó al servicio de las ideologías y sirvió a los poderes establecidos. La historia educativa también es necesaria a la historia social por cuanto la escuela transmitió imaginarios colectivos y condicionó los procesos de movilidad e igualdad. Obviamente, es útil a la historia de la ciencia en la medida en que la academia configuró las disciplinas y la difusión del conocimiento.

Todo lo anterior ha promovido intereses múltiples en el campo de la historia de la educación y ha aminorado, en parte al menos, la crisis que nuestra disciplina viene padeciendo en las áreas de estudio más específicas, como lo son las relacionadas con la formación de los enseñantes y la pedagogía.

MARIA HELENA CAMARA BASTOS é professora na Pontifícia Universidade Católica do Rio Grande do Sul. Professora visitante na Università degli studi di Macerata/Itália.

Endereço: Rua Eng. Álvaro Nunes Pereira, 340/906 - 90570-110 - Porto Alegre - RS - Brasil.

E-mail: mhbastos1950@gmail.com.

Recebido em 23 de abril de 2016.

Aceito em 11 de julho de 2016. 